\title{
NEP (Children @School): An instrument for measuring environmental attitudes in middle childhood
}

\begin{abstract}
While there are many environmental education programs for children, few studies have used an appropriately developed scale for evaluating how such education might impact children's environmental orientations. The research presented in this paper adapted the NEP (New Ecological Paradigm) for children scale to develop a new instrument for measuring children's environmental attitudes; the NEP (Children@School). The NEP (Children@School) has been developed by analysing the impact of the design of physical learning spaces on children's environmental attitudes.
\end{abstract}

Factor analysis indicated that NEP (Children@School) has three dimensions: Children's Environmental Attitudes towards Human Intervention, Children's Environmental Attitudes via ESD at School, and Children's Environmental Attitudes towards Eco-rights. We argue that NEP (Children@School) can meaningfully measure the impact of learning spaces on children's environmental attitudes. While the instrument was developed for use in Australia, it has been designed for global applicability.

Keywords: Children's Environmental Attitudes; school design; NEP (Children@School); Factor analysis; Estimate reliability

\section{INTRODUCTION}

This papers posits a tool for measuring how much the physical environment of schools impacts childrens' environmental attitudes. Such a tool offers a way of testing the efficacy of architectural design strategies, such as the inclusion of visible environmentally sustainable design (ESD) 
features, for improving children's attitudes to the natural envronment. The tool is an adaptation of the NEP for Children; revising the original to make it suiteable for the particular contexts of evaluating the design of schools.

A key argument underpinning research on learners' environmental attitudes and behaviours is that it is crucial to understand environmental attitudes because these inform pro-environmental behaviour, which is the ultimate goal of environmental education (Rickinson, 2001). Thus, environmental attitudes research is critical for understanding what determines attitudes, and therefore for understanding how environmental education programs impact environmental attitudes and behaviours (Newhouse, 1990). Or as Kwan and Miles put it, as young people hold environmental attitudes, "to achieve success in environmental education teachers need to identify and draw on children's opinions about environments" (Kwan \& Miles, 1998, p. 12).

As much of the data on what impacts environmental learning is quantitative in nature (Rickinson, 2001), quantitative measurement is one of the most widely accepted methods of measuring environmental attitudes (Riley E. Dunlap, Van Liere, Mertig, \& Jones, 2000; Larson, Green, \& Castleberry, 2011; Leeming, Dwyer, \& Bracken, 1995; Manoli, Johnson, \& Dunlap, 2007; Noe \& Snow, 1990b). This paper investigates the use of a quantitative approach to evaluate how environmental attitudes are impacted by learning contexts. In particular, the paper proposes an instrument (the NEP (Children @School)) for measuring how the physical environment of schools, rather than the pedagogical or psycho-social environments, might impact childrens' environmental attitudes whilst at school (and thus, it might be hoped, beyond). For while there are many environmental education programs for children, few studies have been able to develop appropriate scales for evaluating the impacts of the learning contexts of these programs on childrens' environmental attitudes. 
For an instrument to be appropriate for use with children, apart from being reliable and valid it needs to be specifically designed for their age. Thus, 'instruments that exclusively employed complex question structure to address broad attitudinal dimensions and global concepts in adult and teenage populations are less relevant for younger children' (Larson et al., 2011, p. 73). While researchers have developed some child-appropriate environmental attitude assessment instruments, such as CATES (Musser \& Malkus, 1994), CHEAKS (Leeming et al., 1995), 2-MEV (F. X. Bogner \& Wilhelm, 1996), and CEP (Larson et al., 2011), few of these have been designed to address children's environmental attitudes within educational contexts and none have been designed to measure the impact of the design of physical learning spaces on children's environmental attitudes. This paper proposes an adaptation of the NEP for Children scale to measure children's environmental attitudes in schools; the NEP (Children@School). While the NEP (Children @School) adapted the NEP for Children for Australian use, its design makes it appropriate for wider global use. In the development of the scale, 624 children, aged 10 to 12 years-old (defined by Newman \& Newman as in the Middle Childhood life-stage (Newman \& Newman, 2014)), completed a survey on their environmental attitudes towards their school learning environments.

It was found that the NEP (Children@School) scale has three dimensions: Children's Environmental Attitudes towards Human Intervention, Children's Environmental Attitudes via ESD at School, and Children's Environmental Attitudes towards Eco-rights. When the estimate reliability omega value was calculated for each of these factors, the results indicated that the scale can reliably measure the the efficacy of the physical design of learning spaces for improving children's attitudes to the natural envronment. 


\section{BACKGROUND}

Environmental sustainability has become a major social issue (Wilson \& Knopt, 2002). As environmental sustainability is largely about human choices and actions, each individual has a great deal to contribute towards environmental change (Mayer \& Frantz, 2004). To understand how environmental problems are perceived by individuals, it is necessary to investigate the attitudes that inform human relationships towards their physical environments. Attitude "implies more than simply the knowledge of a body of factual information; instead, it implies a combination of factual knowledge and motivating emotional concern, which result in a tendency to act" (Stapp et al., 1969, p. 15). Attitudinal variables includes those factors that deal with "the individual's feelings, pro or con, favourable or unfavourable, with regard to particular aspects of the environment or objects related to the environment" (Hines, Hungerford, \& Tomera, 1987, p. 4). As such, it is argued that environmental attitude research is critical for understanding what determines attitudes (Newhouse, 1990), and ultimately contributing towards pro-environmental changes.

One of the main objectives of environmental education is to modify and promote people's environmental behaviour. Since, one of the determinants of behaviour is attitude (Kraus, 1995), it is important to evaluate environmental attitudes that facilitate modifying environmental behaviours (Pooley \& O'Connor, 2000). Acknowledging attitude as one of the formative agents in environmental literacy, researchers such as Leeming, Dwyer and Bracken (1995) believe that research on children's environmental attitudes needs to be furthered because 'early attitudes and knowledge shape the later thinking of adolescents and adults' (Leeming et al., 1995, p. 23). Therefore, as it has been found that children gain environmental knowledge, and develop environmental attitudes, as early as kindergarten (Bryant \& Hungerford, 1977), the importance is 
clear of studying and being able to measure children's environmental development and orientations, and thus of being able to determine how such orientations can best be informed.

Teaching via school curricula is the primary method for environmental education. However, other less directly observable and more implicit methods have also been developed, such as learning through participation (hands on experiences) or learning through 'knowing eye' (visual literacy). Taylor and Enggass (2009) believe that once we start to 'read' an environment, we have cultivated a knowing eye. The visual literacy gained from a knowing eye enables the occupants of a space to read, see, deeply perceive, and critically analyse that physical environment. The physical environment is therefore also referred to as a 'three dimensional textbook', or 'silent curriculum', which might not be palpable but which impacts the learning experiences of users of a space (Taylor \& Enggass, 2009, p. 25). As such, the wider study that led to the development of the NEP (Children@School) aimed to determine if learning via knowing eye allows the design of school learning spaces to be used as pedagogic tools for environmental education.

According to the literature, environmental attitudes and behaviours are believed to be impacted by the duration of exposure to incentives that encourage pro-environmentalism (Partain, 1980). As most of the environmental initiatives in schools are short-term and do not provide students a long period of exposure to environmental issues, the role of the school built environment is of paramount importance because it offers students a semi-permanent visual exposure. As 'physical elements in the environment can act as visual cues or prompts for learning' (Wilks, 2010, p. 9), design can be seen to have a pedagogical value. Moreover, as we have discussed elsewhere (Izadpanahi, Elkadi, \& Tucker, 2015) sustainability features that have been added to or included in redesigned school learning spaces have been shown to inform patterns of pro-environmental attitudes. 
Before moving on to discuss the development of the NEP (Children @ School), and how it acknowledges the potential use of school design as a pedagogy for enhancing environmental attitudes, the theoretical background of the use of such quantitative instruments is summarised. First, the development of environmental attitudes scales is discussed, including the New Ecological Paradigm (NEP) - the source of the NEP for Children. A discussion of environmental attitudes scales for children will then precursor a description of the NEP for children-2007 (Manoli et al.) - the basis of NEP (Children @School).

\section{Environmental attitudes scales for adults}

Efforts to measure environmental attitudes have led to the development of many assessment instruments (Leeming et al., 1995). Although these instruments share a similar aim, different scales have different approaches depending on the research objectives. In a study by Werner, Turner, Shipman, Twitchell, Dickson, Bruschke, and von Bismarck (1995), attitudechange due to participation in a free curb-side recycling program were measured using a 40-item questionnaire that tapped 'general recycling attitudes, and behaviours, attitudes towards the curbside pick-up firm, and self-concept as a recycler' (Werner et al., 1995, p. 201). In another study, Tuncer, Ertepinar, Tekkaya , and Sungur (2005) used a 45-item Likert questionnaire to measure the effect of school type and gender on students' environmental attitudes. The questionnaire consisted of four dimensions: 'awareness of environmental problems, national environmental problems, solutions to the problems, and awareness of individual responsibility' (Tuncer et al., 2005, p. 215). Schindler (1999) created the survey of Environmental Issue Attitude in order to measure college students' attitudes. This 20-item survey also measured demographics, ecology knowledge, and self-reported changes in behaviours toward the environment. 
While there is no universal instrument to gauge environmental attitudes, the New Ecological Paradigm (NEP) is perhaps the most widely used instrument for measuring environmental attitudes (Riley E. Dunlap et al., 2000; van Petegem \& Blieck, 2006). Employing the NEP, a scale rigorously tested for internal consistency and validity, provides the opportunity for researchers to compare the results of different studies, and thus consistently build upon knowledge about environment and attitudes. Unlike previous environmental scales, which predominantly focused on attitudes towards specific problems such as energy consumption, waste disposal, and air/water pollution (Albrecht, Bultena, Hoiberg, \& Nowak, 1982), the NEP relates to a more general position about environment (Noe \& Snow, 1990b). Considering the scope and limits of the other environmental attitudes scales reviewed above, the NEP is a clear choice for adaptation for measuring the environmental attitudes of children. Thus, before moving on to explain the NEP (Children@School), the following sections will describe the development process and characteristics of the NEP.

\section{- New Environmental Paradigm (NEP)}

Dunlap and Van Liere (1978) developed the New Environmental Paradigm scale to investigate "whether a more general position about society and its resources existed among American public' (Noe \& Snow, 1990b, p. 21). The twelve items of the New Environmental Paradigm 'focused on beliefs about humanity's ability to upset the balance of nature, the existence of limits to growth for human societies, and humanity's right to rule over the rest of nature' (R. E. Dunlap, Liere, Mertig, \& Jones, 2000, p. 427).

In 2000, Riley, Dunlap, Van Liere, Mertig and Jones modified the New Environmental Paradigm to the New Ecological Paradigm (NEP). This new scale was designed to improve upon several aspects of the original scale by covering a broader range of environmental worldviews, 
providing better balance of pro-environmental and anti-environmental items, as well as removing out-dated terminology. The NEP aimed to assess five key factors: (1) limits to growth, (2) antianthropocentrism, (3) fragility of nature's balance, (4) rejection of human exemptionalism, and (5) belief in eco-crisis. As all five factors were assessed using three items specifically designed for each, the NEP has a total of fifteen items.

\section{- $\quad$ The NEP scale reliability}

'Reliability of a scale is an indication of how accurately and repeatably it determines whatever it reports to measure' (Schindler, 1999, p. 16). The NEP scale has been subjected to a good deal of reliability testing and has been found to have reasonably strong internal consistency (R. E. Dunlap et al., 2000). As Dunlap (2008) reports, 'alpha averaged .71 for all 140 samples' (R.E. Dunlap, 2008, p. 11) in 68 studies that employed different versions of the NEP. The NEP is reported to have stronger internal consistency in the context of more developed nations.

\section{- Cross-contextual and cross-cultural applicability of the NEP}

It has been found that 'culture influences the structure of environmental beliefs' (Bechtel, Corral Verdugo, \& de Queiroz Pinheiro, 1999, p. 123). In order to control for the impact of cultural differences on research, a scale needs to be used in a corresponding and homogeneous context to which the scale was developed. Alternatively, a scale should be tested in terms of reliability and cross-cultural applicability prior to being applied in a culture for where the scale was not originally designed. A review of the literature reveals that different versions of the NEP have been administered across thirty-six nations (R.E. Dunlap, 2008). Noe and Snow (1990) write that 'the NEP scale has also been administered in ethnic and cross-cultural studies seemingly without problems in translation' (Noe \& Snow, 1990a, p. 28). While the NEP was first developed for use in the United States of America, it has been utilized in Latin American countries (Bechtel et al., 
1999; Vikan, Camino, Biaggio, \& Nordvik, 2007), developing countries (Furman, 1998), and European countries (Gooch, 1995).

The NEP has also been used in Australia, the country for which the NEP (Children @ School) was developed. Casey and Scott (2006) used the NEP to measure the environmental concern of 292 participants from 126 urban and rural locations across Australia. They found that 'the sociodemographic bases of environmental concerns in Australia appear to be quite similar to the sociodemographic bases of such concern found in US studies' (Casey \& Scott, 2006, p. 63). They reported that Cronbach alpha for the NEP scale in their study (.84) compared favourably with the corresponding reliability estimates in the US studies: .78, .82 (Australia. Dept. of Sustainability, 2011), and .83 (Riley E. Dunlap et al., 2000). Thus, it can be posited that the NEP has demonstrated good cross-cultural applicability.

\section{- Dimensionality of the NEP}

On some occasions the variables involved in analysis are not comprised of a single construct. Rather, a specific variable can be composed of two or more underlying variables. These underlying variables are referred to as dimensions or factors. To identify these dimensions or factors, factor analysis is used as a statistical technique in this paper.

While evidence supports the overall reliability and cross-cultural applicability of the NEP, there is a lack of consensus on whether the NEP measures a single construct or is inherently multidimensional. While many studies have reported that the NEP is a uni-dimensional scale, thus indicating that all items were seemingly tapping a single attitudinal domain (R. E. Dunlap et al., 2000; Edgell \& Nowell, 1989; Lefcourt, 1996; Noe \& Snow, 1990b; Shin, 2001; Slimak \& Dietz, 2006; Steg, Dreijerink, \& Abrahamse, 2005), several other studies have reported that the NEP consisted of two or more factors (Albrecht, Bultena, Hoiberg, \& Nowak, 1982; Bechtel et al., 1999; 
Corral-Verdugo, Bechtel, \& Fraijo-Sing, 2003; Riley E Dunlap \& Van Liere, 1978; Gooch, 1995; Noe \& Snow, 1990a; Shetzer, Stackman, \& Moore, 1991).

\section{Scales to measure children's environmental attitudes}

While children's understanding of their relationship with and impact upon the environment is of interest to both researchers and educators, there have been few studies that have used appropriately developed scales for evaluating children's environmental attitudes. For a scale to be appropriate for use with children, apart from being reliable and valid it needs to be specifically designed for their level of comprehension. Thus, 'instruments that exclusively employed complex question structure to address broad attitudinal dimensions and global concepts in adult and teenage populations are less relevant for younger children' (Larson et al., 2011, p. 73). As shall be discussed now, researchers have developed some child-appropriate environmental attitude assessment instruments, such as CATES (Musser \& Malkus, 1994), CHEAKS (Leeming et al., 1995), 2-MEV (F. X. Bogner \& Wilhelm, 1996), and CEP (Children's Environmental Perceptions Scale) (Larson et al., 2011).

\section{- CATES-1994}

The Children's Attitudes toward the Environment Scale (CATES) was developed by Musser and Malkus (1994) to measure environmental attitudes of grade-school children. The scale items reflect children's knowledge of environmental issues. There have been different opinions about the psychometric properties of the scale. Smith-Sebasto and Semrau (2004) used CATES to evaluate an environmental education program at the New Jersey School of Conservation. Their primary goal was to assess the effect of the NJSOC program on students' attitudes towards environment. Both Musser and Malkus (1994) and Smith-Sebasto and Semrau (2004) report that 
CATES has logical internal consistency reliability (Cronbach alpha $=0.70)$ and high test-retest reliability $(0.68, \mathrm{p}<0.001)$. On the contrary, some studies have raised the issue that CATES has poor test-retest reliability (Kim, Zeman, \& Kostareva, 2007). Researchers have suggested that CATES has not been commonly used because it has a bipolar answer structure that does not give children variety of choices to select from (Manoli et al., 2007).

\section{- $\quad$ CHEAKS-1995}

The Children's Environmental Attitude and Knowledge Scale (CHEAKS) (Leeming et al., 1995) was derived from an adult scale developed by Maloney, Ward, and Braucht (1975), and is used to gauge ecological attitudes and knowledge. According to the developers, this scale has been shown to have acceptable levels of validity and reliability. CHEAKS is comprised of two subscales. One sub-scale assesses attitude and has thirty-six items (twelve items of verbal commitment, twelve items of actual commitment, twelve items of affect). The other sub-scale assesses knowledge and has thirty items. The attitudinal items were sampled systematically from six content-dependent sub-domains (water, energy, animals, recycling, pollution, and general issues). The knowledge sub-scale systematically sampled the same six content-dependent subdomains (Leeming et al., 1995).

Evans, Brauchle, Haq, Stecker, Wong, and Shapiro (2007) raised some criticism about CHEAKS. They stated that this scale includes difficult items for children to understand. The scale also includes items that children do not generally have any control over. The forced choice response format of CHEAKS can also lead to children becoming disinterested with the task at hand (Johnson \& Manoli, 2011). While CHEAKS has generally strong psychometric properties (WalshDaneshmandi \& MacLachlan, 2006), 'it lacks a clearly formulated theoretical basis for its structure' (Johnson \& Manoli, 2011, p. 86), and is considered to be too long (sixty-six items) for 
administering to children.

- $\quad M E V-1996$

The 2-MEV scale was developed by Bogner and Wilhelm (1996) to gauge adolescents' concern towards the environment, and was used to determine the effectiveness of educational programs. The first version of the 2-MEV scale was designed for German students aged from ten to sixteen years old. The scale had sixty-nine items and was revealed to have several subscales such as attitudes, verbal commitment, and actual behaviour. Following on from several studies that included students from Denmark, Germany, Switzerland, and Ireland, the number of scale items was reduced to twenty (F. X. Bogner, 1998a, 1998b; F. X. Bogner, 1999; F. X. Bogner \& Wiseman, 1997, 1998; Wiseman \& Bogner, 1997). This scale continues to be used (F. Bogner, 2000; F. X. Bogner, 2002; F. X. Bogner, Brengelmann, \& Wiseman, 2000; F. X. Bogner \& Wiseman, 2002a, 2002b). Johnson and Manoli (2011) modified the scale further to make it appropriate for children aged between nine and twelve years old in the US. The revised 2-MEV scale has sixteen items and is capable of measuring changes in participants' environmental attitudes before and after they participate in 'Earth' education programs (Johnson \& Manoli, 2011). The revised 2-MEV scale seemed to have the potential to be used in the current study. However, the children's version of this scale has only been used in the US. As such, the realibility of this scale in the Australian context was uncertain.

\section{- CEPS-2011}

The Children's Environmental Perceptions Scale (CEPS) was developed to measure perceptions of nature held by children aged between six to thirteen years old in US (Larson et al., 2011). The CEPS measures two distinct components of environmental orientation: eco-affinity and eco-awareness. Eco-affinity items are identified as reflecting 'personal interest in nature and 
intentions to engage in pro-environmental behaviour, and Eco-awareness items reflects a cognitive grasp of environmental issues related to the general importance and sustainability of natural ecosystems' (Larson et al., 2011, p. 83). The CEPS was meant to help researchers determine the ways children perceive the natural world, and 'identify cognitive and affective aspects of existing environmental education programs that need improvement' (Larson et al., 2011, p. 72). The CEPS is a psychometrically sound scale and contains fewer items than the CHEAKS and CATES scales and thus requires less time to administer (Leeming et al., 1995; Musser \& Malkus, 1994). However, the CEPS has some shortcomings in terms of its applicability to a study of the impact of learning spaces on environmental orientations, for most of the CEPS items ask about plants and animals. A study on learning spaces requires a more holistic measure covering a broader range of environmental issues, such as orientations towards energy consumption and waste reduction. Moreover, the CEPS has not been tested in different cultural contexts - a clear problem for studies outside of US .

\section{- NEP for Children-2007}

The most widely used attitude scale for adults is the New Ecological Paradigm (NEP) (Manoli et al., 2007). Manoli, Johnson, and Dunlap (2007) adapted the NEP to make it an appropriate scale to use with children. This scale was called the NEP for Children. This scale includes ten items and has a five-point Likert-scale scoring system from 1 (strongly disagree) to 5 (strongly agree). NEP for Children is appropriate for use with children aged between ten to twelve years old. Manoli and colleagues report that the NEP for Children measures the same three interrelated dimensions as the NEP: Rights of Nature, Eco-Crisis, and Human Exemptionalism (the belief that humans are exempt from the constraint of nature). However, they also found that 'it is possible to treat the scale as a unidimensional measure providing one overall score on the 
anthropocentric to ecocentric continuum' (Manoli et al., 2007, p. 11).

One of the limitations of NEP for Children relates to the origin of the NEP scale. NEP was originally designed to measure the environmental world view of American people. Therefore, some of the social and cultural aspects that informed it were unique to American societies (Ogunbode, 2013). This issue has also been stated by the developers of the scale, for according to Manoli and colleagues, NEP for Children should be used with 'larger numbers of students in a variety of locations' (Manoli et al., 2007, p. 11). However, unlike some of the previously discussed scales, NEP for Children has been shown to be statistically reliable when used in Australia (Manoli et al., 2007), and therefore could be used in this context with a high level of confidence.

Considering the scope and the limits of the environmental attitudes scales reviewed above, the ten-item NEP for Children by Manoli and colleagues (2007) was adapted as the basis for the study of the impact of learning spaces on the environmental orientations of middle childhood school pupils in Australia. The adapted scale was named NEP (children@School). NEP (children@School) underwent a validity and reliability test through a pilot study and then a main study as described in the methodology section.

\section{METHODOLOGY}

The NEP for Children was revised in in two stages: first via a pilot survey and then, nearly a year later, via the survey of 624 children from seven schools. Four of the schools were conventionally designed, the other three were designed with ecological sustainability in mind and included highly visisble ESD features that are incorporated into school lessons. The The NEP (Children@School) was thus developed by analysing the impact on children's environmental attitudes of ESD in their learning spaces. 


\subsection{Participants}

\section{Rationale for selecting two contrasting types of learning spaces}

The impacts on environmental attitudes of two contrasting types of learning spaces in Victoria, Australia were compared in the study: (1) schools designed with ecological sustainability in mind, and (2) conventionally designed schools. The ResourceSmart AuSSI Vic rating system was used for identifying schools that could be considered as being designed for ecological sustainability. The ResourceSmart AuSSI Vic is the most frequently used method for determing the sustainability credentials of Victorian primary schools. Although ResourceSmart AuSSI VIC does not focus on design credentials, it does consider school performance in terms of water, energy, biodiversity and management; qualities that are very closely connected to design. There were twenty-six 5 star schools in Victoria by 2013 (AuSSIVic, 2013). Only three out of the pool of twenty-six sustainable primary schools made themselves available for the data collection of this study. The sustainability characteristics of these schools are detailed below.

The first school had large areas of solar panels and water tanks for harvesting rainwater designed to be highly visible from the children's play ground. The school also had ten large water tanks in total, with messages printed on them such as: every drop counts; be water wise; learn water- live water; save water-save life; our water-our future. There was also a rainwater calculator for children to gauge how much water is saved in the tanks. Moreover, there were outdoor learning spaces, playgrounds constructed of natural materials, and a hen house.

The second school had developed a sustainability centre where students can experience animal husbandry, growing plants and vegetables, propagating plants, planting, composting, and associated scientific concepts. It utilised solar panels, water tanks, and numerous outdoor learning 
spaces. This school did not use air conditioners for cooling the classrooms, rather the school buiding was designed for natural ventilation and in some cases ventilation fans were used.

The third school had energy and water audit equipments for maintaining the records of resource consumption that could be accessed easily by both students and staff. The trees in the outdoor learning spaces were selected for their low water use, and natural materials were used in play areas to reduce environmental impact. The addition of compost and outdoor eating areas, and adoption of a biodiversity module to inform ideas for developing the school grounds were among other measures taken in this school.

It should be noted that the three selected sustainable schools had very good access to resource-conservation facilities. Equipment such as energy meters and water meters, as explicit examples of facilities in these schools, allow children to control and monitor resource consumption. These schools use clean, non-polluting and renewable energy sources, such as solar energy. The schools also have gardens that allow children to grow their food locally. Although growing food might be a symbolic action at these schools, for limited quantities are grown, the acticivity can be seen to encourage children to engage in pro-environmental behaviours.

Four conventional primary schools in Victoria were also randomly chosen, each largely consisting of buildings constructed in the last 40 years. The conventional schools all lacked the physical attributes that could potentially promote environmental attitudes. Thus, they did not have food growing gardens, compost bins that could explicitly communicate sustainable food-growing principles, nor solar panels and water tanks located in visually-exposed places that chould be incorporated into learning. In all of the sustainably designed schools, solar panels and water tanks were placed around or as part of children's playgrounds so students could see them, and could gauge their water and energy consumption through monitoring equipment used on an everyday 
basis. Moreover, all of the conventional schools used reversed cycle air conditioners for heating and cooling the educational spaces rather than employing passive strategies that could be communicated to children. The consistent lack of such phyisical attributes in the four nonsustainable school buildings informed their classification in the 'conventional' schools category.

The difference in the number of schools selected from each category can be explained by the desire to have a near equal sample size of children in each type of school.

\section{Children}

The participating children included 624 students in the fourth, fifth, and sixth grades, with an age range of ten to twelve years old. The children comprised $42 \%$ males and $58 \%$ females. The children who participated in data collection were simply those students who were present on the day of survey and were willing to take part. Those students who wished to attend were asked to fill out a consent form. The grade level composition of the participants was: 244 children from grade four (ages nine to ten), 169 from grade five (ages ten to eleven), and 211 from grade six (ages eleven to twelve). Of the 624 surveys, 387 were from students enrolled at schools designed for sustainability. The other 237 surveys were from students enrolled at conventional schools.

\subsection{Materials and procedure}

In order to develop NEP (Children@School), six items related to the ecologically sustainable design $\left(\mathrm{ESD}^{1}\right)$ of school buildings and outdoor classrooms were considered for addition to the NEP for Children:

- I would be willing to go to a school that is a part of nature;

- I believe that artificial light in classrooms should be generated by solar panels;

- It makes me feel bad to use recycled water for watering the garden or flushing school toilets;

\footnotetext{
${ }^{1}$ Ecologically Sustainable Design
} 
- I would be willing to grow food in the school garden;

- I feel more connected with nature when classes are held in outdoor spaces;

- It makes me feel better when we have natural daylight rather than artificial light in classrooms;

Experts from different areas of specialization, including primary school teachers, science and environmental educators, and ecology and sustainable design university lecturers examined the initial NEP (Children@school) questionnaire for both content and face validity. They checked the content, comprehensibility and clarity of the items as recommended by (Erdogan, Ok, \& Marcinkowski, 2012). Consequently, some sentences were re-worded and shortened, and some technical terms were replaced by terms more familiar to children. Table 1 summarises the items that experts suggested to modify.

Table 1: Modifications on initial NEP (Children@School) suggested by experts (N.B. the numbers represent the number of the item in the questionnaire sent to experts)

\begin{tabular}{ll}
\hline \multicolumn{1}{c}{ Initial NEP (Children@school) } & \multicolumn{1}{c}{ Revised according to experts' advice } \\
\hline $\begin{array}{l}\text { 6. Nature is strong enough to handle the bad effects of } \\
\text { our modern lifestyle. }\end{array}$ & $\begin{array}{l}\text { 6. Nature will survive even with our bad habits on } \\
\text { Earth. }\end{array}$ \\
\hline $\begin{array}{l}\text { 11. I would be willing to go to a school which is part of } \\
\text { the nature. }\end{array}$ & $\begin{array}{l}\text { 11. I would be willing to go to a school which has a } \\
\text { focus on nature }\end{array}$ \\
\hline $\begin{array}{l}\text { 13. It makes me feel bad to use recycled water for } \\
\text { watering the garden or flushing school toilets. }\end{array}$ & $\begin{array}{l}\text { 13. It makes me feel bad to use recycled water for } \\
\text { watering the garden. }\end{array}$ \\
\hline $\begin{array}{l}\text { 16. It makes me feel better when we have day light } \\
\text { rather than artificial light all day in classroom. }\end{array}$ & $\begin{array}{l}\text { 16. It makes me feel better when we have natural day } \\
\text { light rather than artificial light all day in classrooms. }\end{array}$ \\
\hline
\end{tabular}

Item numbers 6,11 , and 16 were paraphrased to become more comprehensible for children. Item number 13 was changed because it addressed two issues simultaneously, of watering the garden and flushing the toilets, and thus made it difficult for some children to rate. One child might want to use recycled water for watering the garden, but might not like to use that kind of water for flushing the toilet. As asking about two issues at the same time could invalidate the item, and only one dimension (using recycled water for watering the garden) needed to be questioned, this item was changed to 'it makes me feel bad to use recycled water for watering the garden'. Future 
researchers might consider reframing this question in order to retain both concepts in the instrument.

Ethics approval was obtained to collect information from primary school children. According to the approval, all the data was collected anonymously, any participants of the project could withdraw from attending the survey without any adverse consequences, children were asked to freely leave the survey responding if they didn't feel comfortable in any way, and they did not require the researcher's permission to quit the attendance.

\section{Pilot-testing the NEP (Children@School)}

In 2013, the initial draft of the NEP (Children@School) scales was administered in a primary school for pilot testing the appropriateness of the scale for children in grades four to six. The pilot aimed to identify any difficult terms or ambiguous questions. The pilot indicated there were no problematic items on the scale, and that the children could answer the questionnaire without any confusion. Thus, the pilot school data was included in the final analysis as one of the conventional schools.

\section{Main Study}

Later in 2013, the 16-item NEP (Children@School) questionnaires (Table 2) were administered in three schools considered as designed for sustainability and four conventional schools. On the day of testing, forty-five minutes was allocated for data collection. Due to limited resources, it was only possible to collect the data from a maximum of fifty children at a time. In each school, at least one of the teachers assisted with the procedure and supervised the children by encouraging them to answer carefully. Before launching the survey, the researchers ensured that all children understood that the data was anonymous and that the child could terminate the survey at any time without consequences. 


\begin{tabular}{ll}
\hline No. & Item \\
\hline 1 & Plants and animals have as much right as people to live. \\
\hline 2 & There are too many people on earth. \\
\hline 3 & People are clever enough to keep from ruining the earth. \\
\hline 4 & People must still obey the laws of nature. \\
\hline 5 & When people mess with nature it has bad results. \\
\hline 7 & Nature will survive even with our bad habits on earth \\
\hline 8 & People are supposed to rule over the rest of nature. \\
\hline 9 & People are treating nature badly. \\
\hline 10 & If things don't change; we will have a big disaster in the environment soon. \\
\hline 11 & I would be willing to go to a school which has a focus on nature. \\
\hline 12 & I believe that artificial light in classrooms should be generated by solar panels. \\
\hline 13 & It makes me feel bad to use recycled water for watering the garden. \\
\hline 14 & I would be willing to grow food in the school garden. \\
\hline 15 & I feel more connected with nature when classes are held in outdoor spaces. \\
\hline 16 & It makes me feel better when we have natural day light rather than artificial light all day in classrooms. \\
\hline
\end{tabular}

\section{ANALYSIS AND RESULTS}

In order to check the reliability of NEP (Chidren@School), and identify potential underlying dimensions, the scale, as described in section 3.1 and 3.2 below, was subjected to reliability tests and factor analyses.

\subsection{Dimensionality of the NEP (Children@School)}

The psychometric properties of the NEP(Children@School) were evaluated. McDonald's omega ${ }^{2}(\omega)$ was calculated as the measure of reliability. The dimensionality of the scale was checked due to the need to calculate omega for each of the potential subscales - known as factors. Principal component analysis was conducted employing the Varimax rotation method. A KMO value of .803 and Bartlett's Test of Sphericity significance value of .000 indicated that factor analysis was appropriate for this sample.

\footnotetext{
${ }^{2}$ Omega was calculated with $\mathrm{R}$ package. $\mathrm{R}$ is an integrated, interactive environment for data manipulation and analysis that includes functions for standard descriptive statistics (means, variances, ranges).
} 
The principal component matrix identified three potential factors for the scale. These factors were named Human Intervention, Eco-right, and ESD at School. The Human Intervention dimension addresses the type of issues that are mostly the result of long-term, large-scale human intervention in nature. The Eco-right dimension addresses fundamental beliefs towards the environment and included items that are mostly subjective and based on a person's belief system. The ESD at School dimension included items that address sustainability features in school that facilitate children's connectedness with nature, such as outdoor classrooms and food growth in the school garden. These features help inform pro-environmental attitudes in children and provide opportunity to link these attitudes to behaviours through experiential learning.

The rotated loadings ${ }^{3}$ were investigated by an orthogonal rotation approach through the Varimax technique (Table 3). Most of the loadings were higher than .3 as the cut-off for optimal item-loadings (Pallant, 2013) . There were two exceptions for this:

1. Item no. 8 had a loading of .231 under the Human Intervention factor (its highest loading on any factor). However, item no.8 was retained as the reliability of Human Intervention would decrease if it was deleted.

2. Item no.12, which had a loading of .279. This item had a much higher loading on Human Intervention (.506), but it is a theoretically best fit to the factor ESD at School.

Items no.11 and no.4 also had higher loadings on Human Intervention, but they were classified to different factors according to their greater applicability to the conceptual theme of those factors. These items still possess loadings higher than .3 on the allocated factors. Thus, the rotated component loadings suggested that the items could be meaningfully classified into three different factors: (1) Children's Environmental Attitudes towards Human Intervention, (2) Children's

3 Factor loadings represent how much a factor explains a variable in factor analysis. 
Environmental Attitudes via ESD at School, and (3) Children's Environmental Attitudes towards Eco-rights.

Table 3: Principal Component Analysis of the NEP (Children@school) Items with Varimax Rotation

\begin{tabular}{|c|c|c|c|c|}
\hline \multirow[t]{2}{*}{ Scale items } & \multirow{2}{*}{$\begin{array}{c}\text { Three Hypothesized } \\
\text { Factors for } \\
\text { NEP (Children@School) }\end{array}$} & \multicolumn{3}{|c|}{ Loadings } \\
\hline & & 1 & 2 & 3 \\
\hline $\begin{array}{l}\text { 10. If things don't change; we will have a big disaster in the } \\
\text { environment soon. }\end{array}$ & \multirow{6}{*}{ Human Intervention } & .697 & & \\
\hline $\begin{array}{l}\text { 9. People will someday know enough about how nature } \\
\text { works to be able to control it. }\end{array}$ & & .654 & & \\
\hline 5. When people mess with nature it has bad results. & & .379 & & .307 \\
\hline 3. People are clever enough to keep from ruining the earth. & & .435 & & \\
\hline 8. People are treating nature badly. & & .231 & .113 & .033 \\
\hline 2. There are too many people on earth. & & .349 & -.187 & -.302 \\
\hline $\begin{array}{l}\text { 11. I would be willing to go to a school that has a focus on } \\
\text { nature. }\end{array}$ & \multirow{6}{*}{ ESD at School } & .526 & .328 & \\
\hline $\begin{array}{l}\text { 12. I believe that artificial light in classrooms should be } \\
\text { generated by solar panels. }\end{array}$ & & .506 & .279 & \\
\hline 14. I would be willing to grow food in the school garden. & & & .683 & \\
\hline $\begin{array}{l}\text { 15. I feel more connected with nature when classes are held } \\
\text { in outdoor spaces. }\end{array}$ & & & .680 & \\
\hline $\begin{array}{l}\text { 16. It makes me feel better when we have natural day light } \\
\text { rather than artificial light in classrooms. }\end{array}$ & & & .569 & \\
\hline $\begin{array}{l}\text { 13. It makes me feel bad to use recycled water for watering } \\
\text { the garden. }\end{array}$ & & & -.387 & .337 \\
\hline 4. People must still obey the laws of nature. & \multirow{4}{*}{ Eco-Rights } & .472 & & .309 \\
\hline 6.Nature on Earth will survive even with our bad habits & & & & .679 \\
\hline 7. People are supposed to rule over the rest of nature. & & & & .582 \\
\hline 1. Plants and animals have as much right as people to live. & & & & .518 \\
\hline Eigenvalue & & 3.190 & 1.340 & 1.199 \\
\hline Percentage of Variance & & 19.93 & 8.37 & 7.49 \\
\hline
\end{tabular}

The bold figures represent the highest loadings.

\subsection{Reliability of the NEP (Children@School)}

The estimate reliability of Omega was calculated for each of the three identified factors (Table 4). Results show that the first factor had omega value of .66, which could be increased to a respectable value of .71 when item no.2 (there are too many people on earth) was deleted. Deletion of item no. 2 was seen as appropriate because it might be seen as ambiguous for 10-12-year-old children who could see a loss of people as a threat to their wellbeing. Further rationale for deleting 
item no. 2 was that it did not consistently reflect the factor it had the highest loading on: Human Intervention.

The Omega value for factor 2 - ESD at School - increased from .66 to .7 if item no. 13 was deleted. Negative loading of item no.13 on factor 2 indicated the need for reverse coding (De Vaus, 2014), however this item was theoretically in the same direction as its underlying factor as it had already been reverse coded. As such, a possible misconception around the direction of the question (it makes me feel bad to do something good) was seen to contaminate the analysis and thus the item was dropped from the scale. Future researchers might consider reframing this question in order to retain it in the instrument.

The third factor, Eco-rights, had Omega of .57, which although not very high can be argued as acceptable because of the psychological construct of the scale and the diversity of the construct being measured (Kline, 1993). Moreover, some researchers believe that reliability coefficients as low as .5 will suffice in the early stages of research (Nunnally, 1978).

Table 4: Omega values calculated by " $R$ ” for the NEP (Children@School)

\begin{tabular}{llc}
\hline Factors & & omega \\
\hline \multirow{2}{*}{ 1.Human Intervention } & 6 items & .66 \\
\cline { 2 - 3 } & 5 items: item 2 deleted & .71 \\
\hline \multirow{2}{*}{ 2. ESD at School } & 6 items & .66 \\
\cline { 2 - 3 } & 5 items: item 13 is deleted & .7 \\
\hline 3. Eco-Rights & 4 items & .57 \\
\hline
\end{tabular}

Table 5: Identified factors for the NEP (Children@School)

\begin{tabular}{|c|c|c|c|c|}
\hline \multirow[t]{2}{*}{ Scale items } & \multirow{2}{*}{$\begin{array}{c}\text { Three Hypothesized Factors for } \\
\text { the NEP(Children@School) }\end{array}$} & \multicolumn{3}{|c|}{ Loadings } \\
\hline & & 1 & 2 & 3 \\
\hline Item 10 & \multirow{7}{*}{ Human Intervention } & .697 & & \\
\hline Item 9 & & .654 & & \\
\hline Item 5 & & .379 & & \\
\hline Item 3 & & .435 & & \\
\hline Item 8 & & .231 & & \\
\hline Item 11 & & & 328 & \\
\hline Item 12 & & & 279 & \\
\hline
\end{tabular}




\begin{tabular}{|c|c|c|c|c|}
\hline Item 14 & \multirow[t]{3}{*}{ ESD at School } & \multicolumn{3}{|c|}{.683} \\
\hline Item 15 & & \multicolumn{3}{|c|}{.680} \\
\hline Item 16 & & \multicolumn{3}{|c|}{.569} \\
\hline Item 4 & \multirow{4}{*}{ Eco-Rights } & & & .309 \\
\hline Item 6 & & & & .679 \\
\hline Item 7 & & & & .582 \\
\hline Item 1 & & & & .518 \\
\hline Eigenvalue & & 3.190 & 1.340 & 1.199 \\
\hline Percentage of Variance & & 19.93 & 8.37 & 7.49 \\
\hline omega & & .71 & .7 & .57 \\
\hline
\end{tabular}

The bold figures represent the highest loadings.

It is worth underlining that all of the items within the 'Rights of Nature' factor of the Manoli et al. (2007) study have fallen into the 'Eco-right' factor in this study. Moreover, the items classified in 'Eco-crisis' and 'Human Exemptionalism' in Manoli et al. (2007) have been classified within the 'Human Intervention' factor in this study - with some deletions and modifications. Five of the six new items in NEP (Children@School) were grouped within the ESD at School factor. The indication is that the NEP (Children@School) is constituted from fourteen items and three factors, as summarized in Table 5 .

\section{DISCUSSION}

Over several decades, numerous researchers have strived to develop instruments for measuring children's environmental attitudes (F. X. Bogner, 1998a; F. X. Bogner \& Wiseman, 1998; Johnson \& Manoli, 2011; Larson et al., 2011; Leeming et al., 1995; Manoli et al., 2007; Musser \& Malkus, 1994). However, most of these instruments are not largely applicable for measuring the impact of educational settings on environmental knowledge and attitudes. Since children have shown that they gain environmental knowledge and develop environmental attitudes as early as kindergarten (Bryant \& Hungerford, 1977), it is crucial to understand how educational spaces, in which children spend considerable amount of time, can contribute to environmental 
orientation (Bell \& Dyment, 2008; Cole, 2013). This study therefore posits a scale that measures the impact of sustainable design in school settings on children's environmental attitudes.

The results indicate that the NEP (Children@School) can determine the impact of learning space design on children's environmental attitudes, and suggests the scale can be useful in a range of educational settings. In the study that necessitated the development of the scale (Izadpanahi et al., 2015), the NEP (Children@School) was employed to compare the environmental attitudes of Australian children in two types of schools: conventional schools and schools designed for improved ecological sustainability. The result indicated that children who attended sustainably designed schools, compared to those who attended conventionally designed schools, held more pro-environmental attitudes. It follows that sustainable design features in schools can be used as pedagogical tools to elevate children's environmental attitudes (Tucker \& Izadpanahi, 2017), and that the NEP (Children@School) can evaluate the effectiveness of such tools.

While NEP (Children @School)was designed in Australia, it has the potential to be applied in other contexts. The global applicability of NEP (Children @School) derives from the fact that this instrument does not include any question specific to the Australian context that could not be used in other cultures. Thus, future researchers might utilise the scale in different school settings in variety of geographical contexts, and with larger sample sizes, to determine the generalisability of the NEP (Children@School). In addition to school contexts, with minor re-wordings the scale might also prove useful to evaluate the impact on children of other types of sustainably designed environments. Thus, the NEP (Children@School) offers architects, educationalists, and policy makers the possibility of evaluating the effectiveness of sustainable design in learning spaces as a pedagogical tool for enhancing children's environmental attitudes. 


\section{CONCLUSION}

This study aimed to develop a new instrument (NEP (Children @ School)) for measuring children's environmental attitudes while at school so that the impact can be determined of the design of physical learning spaces on children's environmental attitudes. Data collected from 624 primary school children was subjected to factor analysis and reliability testing. The results indicate that a 14-item NEP (Children@School) is appropriate to measure the impact of learning spaces on the environmental attitudes of children from 10 to 12 -years-old. The scale consists of three reliable factors: Children's Environmental Attitudes towards Human Intervention, Children's Environmental Attitudes via ESD at School, and Children's Environmental Attitudes towards Ecorights. Omega Values, as the estimates of reliability, confirmed that each of the three identified factors were statistically reliable. While the NEP (Children @ School) was designed and applied in the context of Australian education for middle childhood, it likely has applicability in other English-speaking contexts. For, as stated, the instrument does not include questions specific to the Australian context, and, moreover, the questions may be suitable for children older than 12 years of age.

\section{REFERENCES}

Albrecht, D., Bultena, G., Hoiberg, E., \& Nowak, P. (1982). Measuring environmental concern: The new environmental paradigm scale. Journal of Environmental Education, 13(3), 39-43. Retrieved from

http://ezproxy.deakin.edu.au/login?qurl=http\%3a\%2f\%2fsearch.ebscohost.com\%2flogin.aspx\%3 fdirect\%3dtrue\%26db\%3dehh\%26AN\%3d8294613\%26site\%3dehost-live\%26scope\%3dsite 
AuSSIVic, R. (2013). Creating sustainable Victorian schools. Retrieved from

\section{http://www.sustainability.vic.gov.au/school}

Australia. Dept. of Sustainability, E., Water, Population and Communities. (2011). Australia state of the environment 2011 in brief: Canberra : Dept. of Sustainability, Environment, Water, Population and Communities, (C2011.

Bechtel, R. B., Corral Verdugo, V., \& de Queiroz Pinheiro, J. (1999). Environmental belief systems: United States, Brazil, and Mexico. Journal of Cross-Cultural Psychology, 30(1), 122-128. doi:10.1177/0022022199030001008

Bell, A. C., \& Dyment, J. E. (2008). Grounds for health: The intersection of green school grounds and health-promoting schools. Environmental Education Research, 14(1), 77-90. doi:10.1080/13504620701843426

Bogner, F. (2000). Environmental perception of Italian and some European non-Mediterranean pupil populations. Fresenius Environmental Bulletin, 9(9-10), 570-581.

Bogner, F. X. (1998a). Environmental perceptions of Irish and Bavarian pupils: An empirical study. The Environmentalist, 18(1), 27-38. Retrieved from http://ezproxy.deakin.edu.au/login?url=http://search.ebscohost.com/login.aspx?direct=true\&d $\underline{\mathrm{b}=e o a h \& A N=638857 \& \text { site }=\text { ehost-live } \& \text { scope }=\text { site }}$

Bogner, F. X. (1998b). The influence of short-term outdoor ecology education on long-term variables of environmental perspective. The Journal of Environmental Education, 29(4), 17-29.

Bogner, F. X. (1999). Empirical evaluation of an educational conservation programme introduced in Swiss secondary schools. International Journal of Science Education, 21(11), 1169-1185. doi:10.1080/095006999290138

Bogner, F. X. (2002). The influence of a residential outdoor education programme to pupil's environmental perception. European Journal of Psychology of Education, 17(1), 19-34. 
Retrieved from

http://ezproxy.deakin.edu.au/login?url=http://search.ebscohost.com/login.aspx?direct=true\&d $\underline{b=e r i c \& A N=E J 824334 \& \text { site }=e h o s t-l i v e \& s c o p e=s i t e}$

http://www.ispa.pt/ejpe/online.asp

Bogner, F. X., Brengelmann, J. C., \& Wiseman, M. (2000). Risk-taking and environmental perception. The Environmentalist, 20(1), 49-62. Retrieved from http://ezproxy.deakin.edu.au/login?url=http://search.ebscohost.com/login.aspx?direct=true\&d $\underline{\mathrm{b}=e o a h \& A N=558656 \& \text { site }=\text { ehost-live } \& \text { scope }=\text { site }}$

Bogner, F. X., \& Wilhelm, M. G. (1996). Environmental perspectives of pupils: The development of an attitude and behaviour scale. The Environmentalist, 16(2), 95-110.

Bogner, F. X., \& Wiseman, M. (1997). Environmental perception of rural and urban pupils. Journal of environmental psychology, 17(2), 111-122. Retrieved from http://ezproxy.deakin.edu.au/login?url=http://search.ebscohost.com/login.aspx?direct=true\&d $\underline{\mathrm{b}=e o a h \& A N=754705 \& \text { site }=\text { ehost-live } \& \text { scope }=\text { site }}$

Bogner, F. X., \& Wiseman, M. (1998). Environmental Perception of Swiss and Bavarian pupils: An empirical Evaluation. Empirische Evaluation von Variablen des Umweltbewußtseins bei Schweizer und bayerischen Schülern/innen., 24(3), 547-566. Retrieved from http://ezproxy.deakin.edu.au/login?url=http://search.ebscohost.com/login.aspx?direct=true\&d $\underline{b=s i h \& A N=27142673 \& \text { site }=\text { ehost-live } \& \text { scope }=\text { site }}$

Bogner, F. X., \& Wiseman, M. (2002a). Environmental perception of French and some western European secondary school students. European Journal of Psychology of Education, 17(1), 3-18. Retrieved from

http://ezproxy.deakin.edu.au/login?url=http://search.ebscohost.com/login.aspx?direct=true\&d $\underline{\mathrm{b}=\text { eric } \& A N=E J 824333 \& \text { site }=\text { ehost-live } \& \text { scope }=\text { site }}$ 


\section{http://www.ispa.pt/ejpe/online.asp}

Bogner, F. X., \& Wiseman, M. (2002b). Environmental perception: Factor profiles of extreme groups. European Psychologist, 7(3), 225-237. doi:10.1027//1016-9040.7.3.225

Bryant, C. K., \& Hungerford, H. R. (1977). An analysis of strategies for teaching environmental concepts and values clarification in kindergarten. The Journal of Environmental Education, 9(1), 44-49.

Casey, P. J., \& Scott, K. (2006). Environmental concern and behaviour in an Australian sample within an ecocentric - Anthropocentric framework. Australian Journal of Psychology, 58(2), 57-67.

Retrieved from

http://ezproxy.deakin.edu.au/login?url=http://search.ebscohost.com/login.aspx?direct=true\&d $\underline{b=e o a h \& A N=28838277 \& \text { site }=\text { ehost-live } \& \text { scope }=\text { site }}$

Cole, L. B. (2013). The teaching green school building: A framework for linking architecture and environmental education. Environmental Education Research, 20, 1-22. Retrieved from http://www.tandfonline.com/doi/pdf/10.1080/13504622.2013.833586

Corral-Verdugo, V. C., Bechtel, R. B., \& Fraijo-Sing, B. (2003). Environmental beliefs and water conservation: An empirical study. Journal of environmental psychology, 23(3), 247-257.

De Vaus, D. A. (2014). Surveys in social research (6 Ed.): Abingdon, Oxon : Routledge.

Dunlap, R. E. (2008). The new environmental paradigm scale: From marginality to worldwide use. The Journal of Environmental Education, 40(1), 3-18.

Dunlap, R. E., Liere, K. D. v., Mertig, A. G., \& Jones, R. E. (2000). New trends in measuring environmental attitudes: Measuring endorsement of the New Ecological Paradigm: A revised NEP scale. Journal of social issues, 56(3), 425-442. Retrieved from http://ezproxy.deakin.edu.au/login?url=http://search.ebscohost.com/login.aspx?direct=true\&d $\underline{b=e o a h \& A N=4702223 \& \text { site }=\text { ehost-live } \& \text { scope }=\text { site }}$ 
Dunlap, R. E., \& Van Liere, K. D. (1978). A proposed measuring instrument and preliminary results: The 'New Environmental Paradigm'. Journal of Environmental Education, 9(1), 10-19.

Dunlap, R. E., Van Liere, K. D., Mertig, A. G., \& Jones, R. E. (2000). Measuring endorsement of the New Ecological Paradigm: A revised NEP scale. Journal of social issues, 56(3), 425-442. Retrieved from

http://ezproxy.deakin.edu.au/login?url=http://search.ebscohost.com/login.aspx?direct=true\&d $\underline{b=a 9 h \& A N=3997995 \& \text { site }=\text { ehost-live \&scope }=\text { site }}$

Edgell, M. C. R., \& Nowell, D. E. (1989). The new environmental paradigm scale: Wildlife and environmental beliefs in British Columbia. Society \& Natural Resources, 2(4), 285. Retrieved from

http://ezproxy.deakin.edu.au/login?url=http://search.ebscohost.com/login.aspx?direct=true\&d $\underline{\mathrm{b}=e i h \& A N=7964157 \& \text { site }=\text { ehost-live \&scope }=\text { site }}$

Erdogan, M., Ok, A., \& Marcinkowski, T. J. (2012). Development and validation of children's responsible environmental behavior scale. Environmental Education Research, 18(4), 507-540. Retrieved from

http://ezproxy.deakin.edu.au/login?qurl=http\%3a\%2f\%2fsearch.ebscohost.com\%2flogin.aspx\%3 fdirect\%3dtrue\%26db\%3deric\%26AN\%3dEJ970784\%26site\%3dehost-live\%26scope\%3dsite

\section{http://dx.doi.org/10.1080/13504622.2011.627421}

Evans, G. W., Brauchle, G., Haq, A., Stecker, R., Wong, K., \& Shapiro, E. (2007). Young children's environmental attitudes and behaviors. Environment and Behavior, 39(5), 635-658.

Furman, A. (1998). A note on environmental concern in a developing country: Results from an Istanbul survey. Environment and Behavior, 30(4), 520-534. doi:10.1177/001391659803000406

Gooch, G. D. (1995). Environmental beliefs and attitudes in Sweden and the Baltic States. Environment \& Behavior, 27(4), 513. Retrieved from 
http://ezproxy.deakin.edu.au/login?url=http://search.ebscohost.com/login.aspx?direct=true\&d $\underline{\mathrm{b}=a s u \& A N=9507232299 \& \text { site }=\text { ehost-live } \& \text { scope }=\text { site }}$

Hines, J. M., Hungerford, H. R., \& Tomera, A. N. (1987). Analysis and synthesis of research on responsible environmental behavior: A meta-analysis. The Journal of Environmental Education, 18(2), 1-8.

Izadpanahi, P., Elkadi, H., \& Tucker, R. (2015). Greenhouse affect: the relationship between the sustainable design of schools and children's environmental attitudes. Environmental Education Research, 1-18. doi:10.1080/13504622.2015.1072137

Johnson, B., \& Manoli, C. C. (2011). The 2-MEV scale in the United States: A measure of children's environmental attitudes based on the theory of ecological attitude. Journal of Environmental Education, 42(2), 84-97. doi:10.1080/00958964.2010.503716

Kim, S. M., Zeman, C., \& Kostareva, O. (2007). Reliability of the children's attitudes toward the environment scale. Psychological reports, 101(1), 117.

Kline, P. (1993). The handbook of psychological testing London ; New York : Routledge, 1993.

Kraus, S. J. (1995). Attitudes and the prediction of behavior: A meta-analysis of the empirical literature. Personality and Social Psychology Bulletin, 21(1), 58-75.

Kwan, T., \& Miles, J. (1998). In the words of children and young people: The opinions and concerns about their environments of some Brisbane school students. Australian Journal of Environmental Education, 14, 11-18.

Larson, L. R., Green, G. T., \& Castleberry, S. B. (2011). Construction and validation of an instrument to measure environmental orientations in a diverse group of children. Environment and Behavior, 43(1), 72-89. Retrieved from http://ezproxy.deakin.edu.au/login?url=http://search.ebscohost.com/login.aspx?direct=true\&d $\underline{b=e r i c \& A N=E J 910770 \& \text { site }=\text { ehost-live \&scope }=\text { site }}$

http://dx.doi.org/10.1177/0013916509345212 
Leeming, F. C., Dwyer, W. O., \& Bracken, B. A. (1995). Children's environmental attitude and knowledge scale: Construction and validation. The Journal of Environmental Education, 26(3), 22-31.

Lefcourt, H. M. (1996). Perspective-taking humor and authoritarianism as predictors of anthropocentrism. Humor: International Journal of Humor Research, 9(1), 57-71. doi:10.1515/humr.1996.9.1.57

Maloney, M. P., Ward, M. P., \& Braucht, G. N. (1975). A revised scale for the measurement of ecological attitudes and knowledge. American psychologist, 30(7), 787.

Manoli, C. C., Johnson, B., \& Dunlap, R. E. (2007). Assessing children's environmental worldviews: Modifying and validating the New Ecological Paradigm scale for use with children. Journal of Environmental Education, 38(4), 3-13. Retrieved from http://ezproxy.deakin.edu.au/login?url=http://search.ebscohost.com/login.aspx?direct=true\&d $\underline{\mathrm{b}=a 9 h \& A N=27718370 \& \text { site }=\text { ehost-live } \& \text { scope }=\text { site }}$

Mayer, F. S., \& Frantz, C. M. (2004). The connectedness to nature scale: A measure of individuals' feeling in community with nature

Journal of environmental psychology, 24(4), 503-515. doi:10.1016/j.jenvp.2004.10.001

Musser, L. M., \& Malkus, A. J. (1994). The children's attitudes toward the environment scale. The Journal of Environmental Education, 25(3), 22-26.

Newhouse, N. (1990). Implications of attitude and behavior research for environmental conservation. The Journal of Environmental Education, 22(1), 26-32.

Newman, B., \& Newman, P. (2014). Development through life: A psychosocial approach: Cengage Learning.

Noe, F. P., \& Snow, R. (1990a). Hispanic cultural influence on environmental concern. Journal of Environmental Education, 21(2), 27-34. Retrieved from 
http://ezproxy.deakin.edu.au/login?url=http://search.ebscohost.com/login.aspx?direct=true\&d $\underline{b=e r i c \& A N=E J 412275 \& \text { site }=\text { ehost-live } \& \text { scope }=\text { site }}$

Noe, F. P., \& Snow, R. (1990b). The new environmental paradigm and further scale analysis. The Journal of Environmental Education, 21(4), 20-26. doi:10.1080/00958964.1990.9941934

Nunnally, J. C. (1978). Psychometric theory: New York, McGraw-Hill [1967].

Ogunbode, C. A. (2013). The NEP scale: measuring ecological attitudes/worldviews in an African context. Environment, development and sustainability, 15(6), 1477-1494.

Pallant, J. F. (2013). SPSS survival manual : A step by step guide to data analysis using IBM SPSS (5 ed.): Crows Nest, N.S.W. Allen \& Unwin.

Partain, J. D. (1980). An assessment of energy cognizance, attitude toward energy conservation, and perceived energy conservation behavior of selected public school educators. (40), ProQuest Information \& Learning, US. Retrieved from http://ezproxy.deakin.edu.au/login?url=http://search.ebscohost.com/login.aspx?direct=true\&d

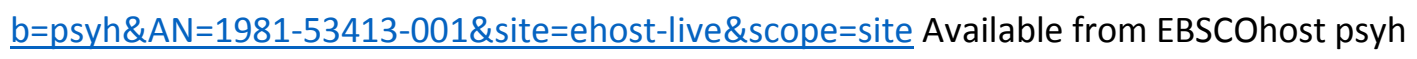
database.

Pooley, J. A., \& O'Connor, M. (2000). Environmental education and attitudes. Environment and Behavior, 32(5), 711-723.

Rickinson, M. (2001). Learners and learning in environmental education: A critical review of the evidence. Environmental Education Research, 7(3), 207-320.

Schindler, F. H. (1999). Development of the survey of environmental issue attitudes. The Journal of Environmental Education, 30(3), 12-16.

Shetzer, L., Stackman, R. W., \& Moore, L. F. (1991). Business-environment attitudes and the New Environmental Paradigm. Journal of Environmental Education, 22(4), 14-21. doi:10.1080/00958964.1991.9943057 
Shin, W. (2001). Reliability and factor structure of a Korean version of the New Environmental Paradigm. Journal of Social Behavior and Personality, 16(1), 9-18.

Slimak, M. W., \& Dietz, T. (2006). Personal values, beliefs, and ecological risk perception. Risk analysis, 26(6), 1689-1705.

Smith-Sebasto, N. J., \& Semrau, H. J. (2004). Evaluation of the environmental education program at the New Jersey school of conservation. Journal of Environmental Education, 36(1), 3. Retrieved from http://ezproxy.deakin.edu.au/login?url=http://search.ebscohost.com/login.aspx?direct=true\&d $\underline{\mathrm{b}=e r i c \& A N=E J 709780 \& \text { site }=\text { ehost-live } \& \text { scope }=\text { site }}$

Stapp, W. B., Bennett, D., Bryan, W., Fulton, J., MacGregor, J., Nowak, P., . . Havlick, S. (1969). The concept of environmental education. Journal of Environmental Education, 1(1), 30-31.

Steg, L., Dreijerink, L., \& Abrahamse, W. (2005). Factors influencing the acceptability of energy policies: A test of VBN theory. Journal of environmental psychology, 25(4), 415-425.

Taylor, A. P., \& Enggass, K. (2009). Linking architecture and education : Sustainable design for learning environments. Albuquerque: University of New Mexico Press.

Tucker, R., \& Izadpanahi, P. (2017). Live green, think green: Sustainable school architecture and children's environmental attitudes and behaviors. Journal of environmental psychology, 51, 209216.

Tuncer, G., Ertepinar, H., Tekkaya, C., \& Sungur, S. (2005). Environmental attitudes of young people in Turkey: Effects of school type and gender. Environmental Education Research, 11(2), 215-233.

van Petegem, P. p. v. u. a. b., \& Blieck, A. (2006). The environmental worldview of children: A crosscultural perspective. Environmental Education Research, 12(5), 625-635.

doi:10.1080/13504620601053662 
Vikan, A., Camino, C., Biaggio, A., \& Nordvik, H. (2007). Endorsement of the New Ecological Paradigm: A comparison of two Brazilian samples and one Norwegian sample. Environment \& Behavior, 39(2), 217-228. doi:10.1177/0013916506286946

Walsh-Daneshmandi, A., \& MacLachlan, M. (2006). Toward effective evaluation of environmental education: Validity of the children's environmental attitudes and knowledge scale using data from a sample of Irish adolescents. The Journal of Environmental Education, 37(2), 13-23.

Werner, C. M., Turner, J., Shipman, K., Twitchell, F. S., Dickson, B. R., Bruschke, G. V., \& von Bismarck, W. B. (1995). Commitment, behavior, and attitude change: An analysis of voluntary recycling. Journal of environmental psychology, 15(3), 197-208. doi:10.1016/0272-4944(95)90003-9

Wilks, S. (2010). A charter for children's learning at the Royal Children's Hospital.

Wilson, E. O., \& Knopt, A. A. (2002). The future of life; The solution. Skeptic, 9(2), 46. Retrieved from http://ezproxy.deakin.edu.au/login?url=http://search.ebscohost.com/login.aspx?direct=true\&d $\underline{b=h u s \& A N=6299894 \& \text { site }=\text { ehost-live } \& \text { scope }=\text { site }}$

Wiseman, M., \& Bogner, F. X. (1997). Environmental perspectives of Danish and Bavarian pupils: Towards a methodological framework. Scandinavian Journal of Educational Research, 41(1), 5371. Retrieved from http://ezproxy.deakin.edu.au/login?url=http://search.ebscohost.com/login.aspx?direct=true\&d $\underline{b=e r i c \& A N=E J 548324 \& \text { site }=\text { ehost-live } \& \text { scope }=\text { site }}$ 


\section{Author biographies:}

\section{Dr. Parisa Izadpanahi}

Dr. Parisa Izadpanahi is a lecturer at School of Built Environment, Curtin University, Australia. Parisa has won several awards such as Graham Treloar Prize-The most outstanding publication in embodied energy and sustainability, and Best Paper Award, PLEA 2014. Her current focus is on smart cities, and environmental design and human's wellbeing.

\section{Associate Professor Dr. Richard Tucker}

Richard Tucker has twenty years of experience as a teacher and researcher in the context of architectural education. He has over 50 publications to his name, reflecting an expertise in five interrelated areas: (1) sustainable design of urban ecologies; (2) the evaluation and perception of sustainable design; (3) teamwork in design; (4) education for the sustainable design of urban ecologies; and (5) built environment design education. Richard has been a team member of grant-funded projects totalling over $\$ 1$ million; eleven investigations including six as project leader. In 2011, Richard became only the 2nd teacher in the discipline of architecture in Australia to be awarded an ALTC Award for Teaching Excellence. 